\title{
Teaching Digital Marketing and Social Media Strategy for the Entertainment Industry
}

\author{
Justin Sinkovich \\ Columbia College Chicago \\ This paper was presented at the 2019 International Summit of the \\ Music \& Entertainment Industry Educators Association \\ March 21-23, 2019
}

$\underline{\text { https://doi.org/10.25101/19.39 }}$

\begin{abstract}
From the largest media organizations, to individual artists and freelancers, digital marketing and social media strategies continue to become increasingly important in the entertainment industry. New technology and the rapid convergence of entertainment-related disciplines both require that students are equipped with a strong knowledge base in their field, as well as the ability to implement content distribution and promotional strategies in rapidly changing technological environments. This session will provide an overview in best practices in digital marketing and how these practices can be implemented into curriculum. The presentation will provide a framework to address overarching theories as they compare and contrast with more traditional marketing theory, and then scaffold principle elements into a campaign. Topics will include setting objectives, goals, and how to measure the results through analytics and key performance indicators (KPI's). Specific tactics in search engine optimization (SEO), email marketing, blogging, long form "evergreen" content creation and distribution will be outlined. Social media promotion is of course a principle focus of digital marketing, and its planning, scheduling, and implementation will be covered in the time allowed. Emerging media such as augmented reality, virtual reality, and gamification and how these technology concepts can potentially be integrated into class content will be discussed.
\end{abstract}

Keywords: digital marketing, social media, search engine optimization, entertainment industry education

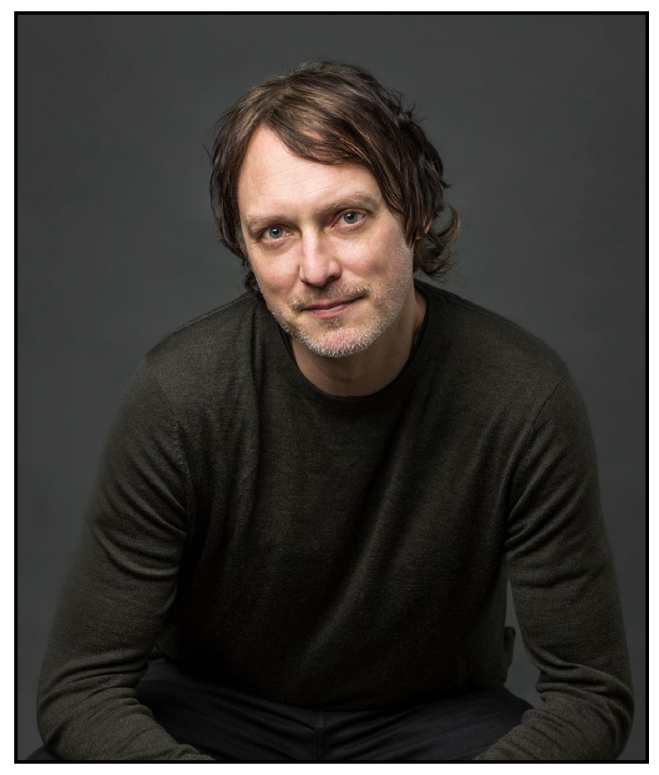

Justin Sinkovich has worked in digital marketing since 1999 when he co-founded the Webby-winning music discovery service Epitonic. Sinkovich continued to focus on digital marketing professionally, particularly in the music industry. While serving as head of digital distribution and promotion at Touch and Go Records, he began teaching e-commerce at Columbia College Chicago as an adjunct instructor. He started teaching full time at Columbia in 2009 and his principle focus has continued to be in this area. He currently teaches New Media Strategies at the graduate level, and a practicum digital marketing agency class that travels to the South by Southwest Interactive Conference. He continues to consult and freelance in social media and digital strategy as well. 


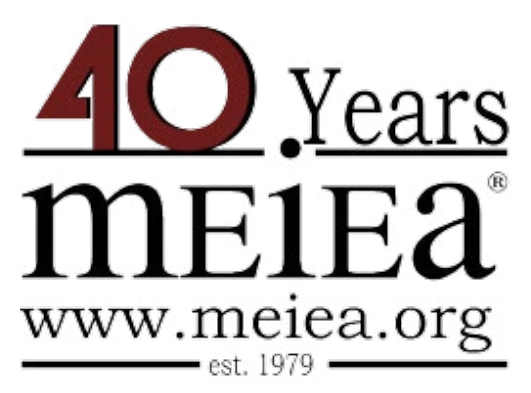

\section{PROCEEDINGS OF THE \\ 2019 INTERNATIONAL SUMMIT \\ OF THE \\ MUSIC \& ENTERTAINMENT \\ INDUSTRY EDUCATORS \\ ASSOCIATION}

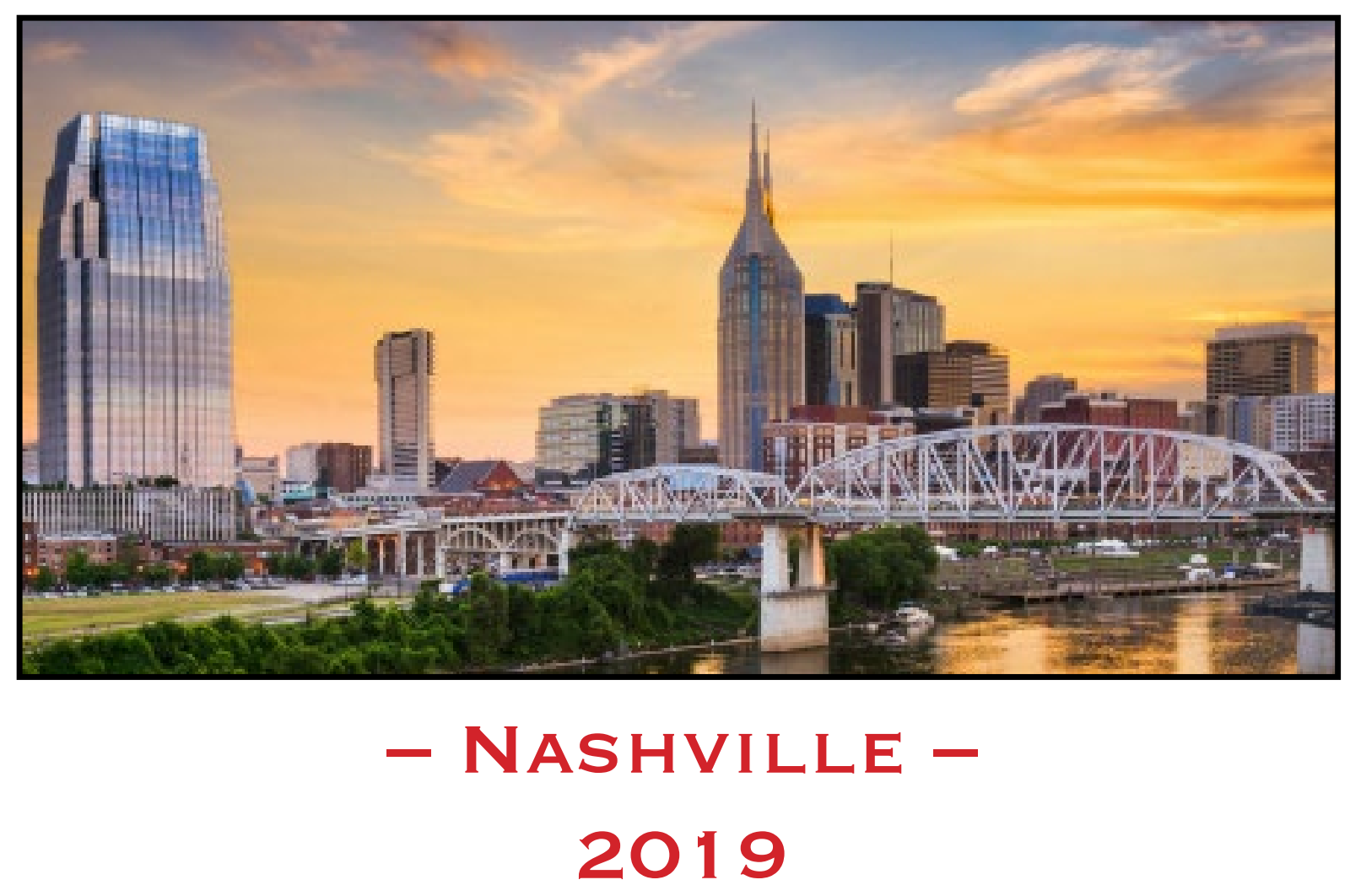

March 21 - 23, $2019 \cdot$ Belmont University - Nashville 